\title{
A Hierarchy of Architectural Design Elements for Energy Saving of Tower Buildings in Korea Using Green BIM Simulation
}

\author{
Kweonhyoung Lee $\mathbb{i}$ and Seungyeon Choo \\ Kyungpook National University, Daegu, Republic of Korea \\ Correspondence should be addressed to Seungyeon Choo; choo@knu.ac.kr
}

Received 10 October 2017; Accepted 19 December 2017; Published 11 February 2018

Academic Editor: Geun Y. Yun

Copyright ( 12018 Kweonhyoung Lee and Seungyeon Choo. This is an open access article distributed under the Creative Commons Attribution License, which permits unrestricted use, distribution, and reproduction in any medium, provided the original work is properly cited.

\begin{abstract}
There is a great interest in building information modeling (BIM) and energy saving worldwide. In reality, however, insufficient studies have been conducted on the development of design methods to perform energy performance analysis. Thus, there is a problem that it is difficult to objectively obtain reliability in energy performance assessment of architectural designs such as scale and size of buildings. In addition, the energy performance analysis is considered as a different field from eco-friendly design methods, and there is another problem that low-carbon design methods more dependent on thermal insulation performance and heating ventilation and air-conditioning (HVAC) system than on original design methods are mainly developed. In order to solve this problem, this study aims to develop design methods capable of considering energy performance from the early design stage. Designers are required to intuitively understand the results through energy performance analysis using BIM tools and to reflect them in design. To this end, this study analyzed the correlation with energy performance using only basic architectural design elements with mass buildings. This has the advantage of establishing more free mass design mass design considering energy performance even if design and main structure are yet to be determined.
\end{abstract}

\section{Introduction}

Currently, there is a growing awareness of environmental pollution in the whole field of architecture, and there is a continuously increasing interest in green building and lowcarbon design methods. According to the World Energy Statistics (Enerdata), it is a fact that the Republic of Korea is urgently required to reduce energy consumption across all industries as the world's eighth largest energy consumer in 2015. Moreover, according to the Korean Statistical Information Service (KOSIS) in Statistics Korea, buildings account for approximately $9.5 \%$ of the overall energy consumption. Although the increase in energy consumption showed a decreasing trend from 2010 to 2015, the total energy consumption has continuously increased. It is considered that the total energy consumption will continuously increase in proportion to the progress of energy efficiency in buildings through the system as demands and expectations for comfort and convenience of buildings increase according to changes in residents' life patterns and awareness.

As shown in Figure 1, apartments account for the largest proportion of the energy consumption, $17.2 \%$ in 2015 . Commercial buildings and schools account for $15.6 \%$ and $13.6 \%$, respectively. In other words, the energy consumption in apartment houses and business facilities showed a continuously increasing trend accounting for $32.9 \%$, and there is a need for a system plan for energy saving of buildings because they account for one third of the overall energy consumption [1].

Conversely, a continuous increase in energy consumption has raised awareness of the need to develop low-carbon design methods in the field of architecture, and there has been active research on the development of highperformance energy architectural technologies using BIM in the academic world. In particular, the use of BIM has the advantage of integrally operating design, construction, and maintenance of buildings. Therefore, it is expected that the 


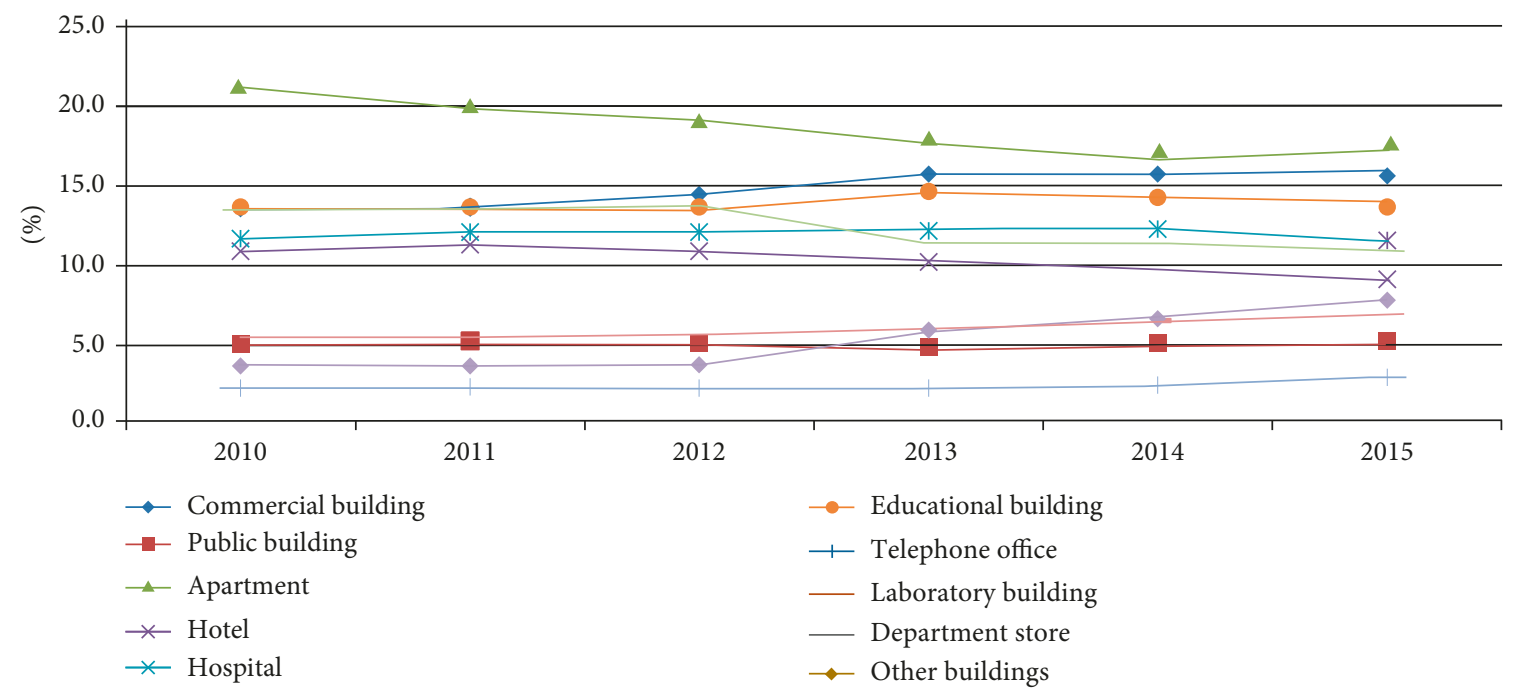

FIgURE 1: Energy use composition ratio by building sector in Korea (\%).

development of construction techniques through energy performance analysis will be highly effective in energy saving. However, with regard to existing design evaluation based on energy performance, analysis and evaluation of energy performance are performed in the intermediate design stage after design and facility system are determined [2]. Thus, there are limitations to the application of the results of energy performance analysis to design: namely, energy performance-based design depending on the insulation performance and facility system was implemented because the problem that energy performance analysis was performed in the later stage of design made it impossible to change the design and main structure determined to improve energy performance.

Therefore, there is need to divide the role into energy performance analysis stages for design and for determining facility system in detail so that mass design considering energy performance can be implemented more freely with undetermined design and main structure. It is considered possible to maximize energy performance and efficiency compared to invested time and support by implementing energy performance analysis and evaluation from the conceptualization stage and clarifying goals for each energy performance analysis.

\section{An Analysis of Current Energy Performance- Based BIM Design}

BIM creates virtual models by $3 \mathrm{D}$ design using computers and makes it possible to reproduce and reprocess information according to the principal agent by inputting information across the whole building life cycle. The availability of BIM has gradually increased because of these advantages and has been accompanied by efforts of each country to preoccupy technologies in related fields. In particular, these studies are based on the construction environment system supporting the Industry Foundation Classes (IFC) format called OPEN BIM, and this enables information exchange even in each life cycle stage of different buildings or different fields of architecture. Moreover, IFC4 is the latest version that was developed from 2008 and released in 2015. It has been gradually enhancing the function for OPEN BIM by solving technical problems such as atypical form, 4D and 5D models' transaction, product library, GIS interoperability, energy simulation, and ifcXML found after releasing IFC2x3 and ensuring the extensibility of IFC in fields related to infrastructure of architectural environment.

Therefore, guidelines for BIM and environmentally friendly building certification have been actively implemented worldwide. Moreover, the development of environmentally friendly guidelines for BIM-based energy performance evaluation is a major issue for each country, and some countries such as the United States, British, and Australia have been making efforts to introduce energy performance evaluation through simulation.

Considering the ease of inputting geometric information such as integrity with BIM and envelope information using 3D shape information, unsteady state thermal load calculation methods are more compatible with BIM tools than analysis tools for steady state thermal load calculation methods and can deal with various shape information. Thus, the former has superior suitability for BIM. However, much information is lost in the process of transmitting BIM model information to energy performance analysis tools. Accordingly, it is urgent to prepare guidelines using BIM and steady state thermal load calculation tools.

With regard to the design criteria for energy saving buildings in South Korea revised in 2015, the construction sector accounts for approximately $36.0 \%$ of the total in energy performance index (EPI) evaluation items, 50 points. However, because other evaluation items such as building layout, floor plan, natural lighting plan, and ventilation plan are divided into recommendations, architectural planning characteristics cannot be reflected. Additionally, 33 points of the construction sector were obtained from the average heat 
transmission coefficient of outer wall, roof, and living room floor on the bottom floor, and even this can be divided into values by insulation and material performance. Therefore, it is difficult to expect energy saving plans by scale, form, and design in the early architectural plan in designing. The "Building Energy Consumption Evaluation Report" also requires heating, hot water supply, air-conditioning, illumination, ventilation, and sum for items such as energy requirement per unit area, energy consumption per unit area, and the primary energy consumption per unit area. Therefore, in reality, energy performance according to design methods such as building scale and form and design is not considered.

And according to the regulations of the certification criteria for building energy efficiency rating in Korea revised in 2015, the energy efficiency to certificate office buildings follows international standards such as ISO 13790 which is a representative steady-state thermal load calculation method. In addition, the evaluation is performed by energy consumption per unit area $\left(\mathrm{kWh} / \mathrm{m}^{2}\right)$ and annual primary energy consumption per unit area $\left(\mathrm{kWh} / \mathrm{m}^{2}\right)$ calculated using programs created to comprehensively evaluate heating, air-conditioning, hot water supply, illumination, and ventilation. However, it is a fact that this method is also more appropriate for evaluating architectural equipment and insulation performance than for evaluating construction plans.

\section{Materials and Methods}

Although many studies related to the development of design methods for energy saving have been carried out, little research has been conducted on design elements such as building form, and most studies focus on exterior design elements such as awnings and electrical and mechanical equipment [3]. In order to remedy this problem, the area of this study was set to the early design stage in the conceptualization stage. In addition, the scale, design, and performance according to rough use of building were determined using BIM to make rational decisions. This study aimed to explore methods for supporting environmentally friendly and low-carbon design through energy performance analysis from the conceptualization stage. Accordingly, the study area was limited to the architectural design elements capable of being extracted using BIM tools in the conceptualization stage among passive architecture design [1].

As a research method, this study aims to analyze the architectural design hierarchy to develop green BIM design methods based on energy performance by analyzing architectural design elements required to determine mass design in the early design stage through the energy performance analysis simulation using BIM tools. Thus, this study analyzed and compared energy consumption by various simulations according to the type of buildings by mass form and characteristics of architectural design elements in the early planning stage.

Tower buildings with a major effect on the surrounding urban environment and high energy consumption due to the large building scale were selected as a target for energy
TABLE 1: LOD step contents.

\begin{tabular}{|c|c|}
\hline LOD & Modeling level of the BIM model by LOD \\
\hline LOD 100 & $\begin{array}{l}\text { Mass at the level of planning work } \\
\text { Shape, volume, and type of the building } \\
\text { Determination of the area, height, volume, position, } \\
\text { incense, etc., of the entire building }\end{array}$ \\
\hline & $\begin{array}{l}\text { Planning step that concept is embodied } \\
\text { Shape, space program, space planning, and spatial } \\
\text { relationship definition }\end{array}$ \\
\hline
\end{tabular}

LOD 200 Planning of approximate floor area, coverage ratio, and floor area ratio, number of floors, floor height, main structure, envelope structure, and equipment system

LOD 200 steps to determine the outline of the concrete contents

LOD 300 Determination of building systems, including detailed installation elements

Modeling of all architectural elements

Modeling steps for actual construction Model the size, shape, quantity, etc., of all determined systems

LOD 400 Model all the elements related to construction, fabrication, and assembly, including details, members, structures, equipment, piping, and wiring The LOD 500 model is the same as the completion model (the modeling data are the same as the actual building)

Maintenance and overall operation of the building

performance analysis. The type of buildings was divided into residential and nonresidential buildings for analysis [4]. Each mass was designed by architectural design elements such as form, window area ratio, floor area, total floor area, volume, and floor height. In addition, modeling and energy performance analysis were performed using Autodesk Revit modeling and Architecture 2016 BIM tools. This study established a hierarchy among architectural planning elements and derived correlations by analyzing the energy performance characteristics for each mass based on the energy performance analysis.

3.1. Level of Development (LOD) Level Configuration of BIM Models. According to AIA Document G203 ${ }^{\mathrm{TM}}-2013$, LOD divides 100 into 500 stages according to the modeling level as shown in Table 1 and divides stages according to the general integrated design process definition without reflecting specific modeling guidelines for particular BIM tools or model content [5]. This study performed modeling at LOD 100 corresponding to the conceptualization stage defined by the Ministry of Land, Infrastructure and Transport (MOLIT) in consideration of the modeling level available in the early design stage [6].

3.2. Type Configuration of Energy Models. This study is roughly divided into residential and business facilities to perform the following experiments according to each building type. 

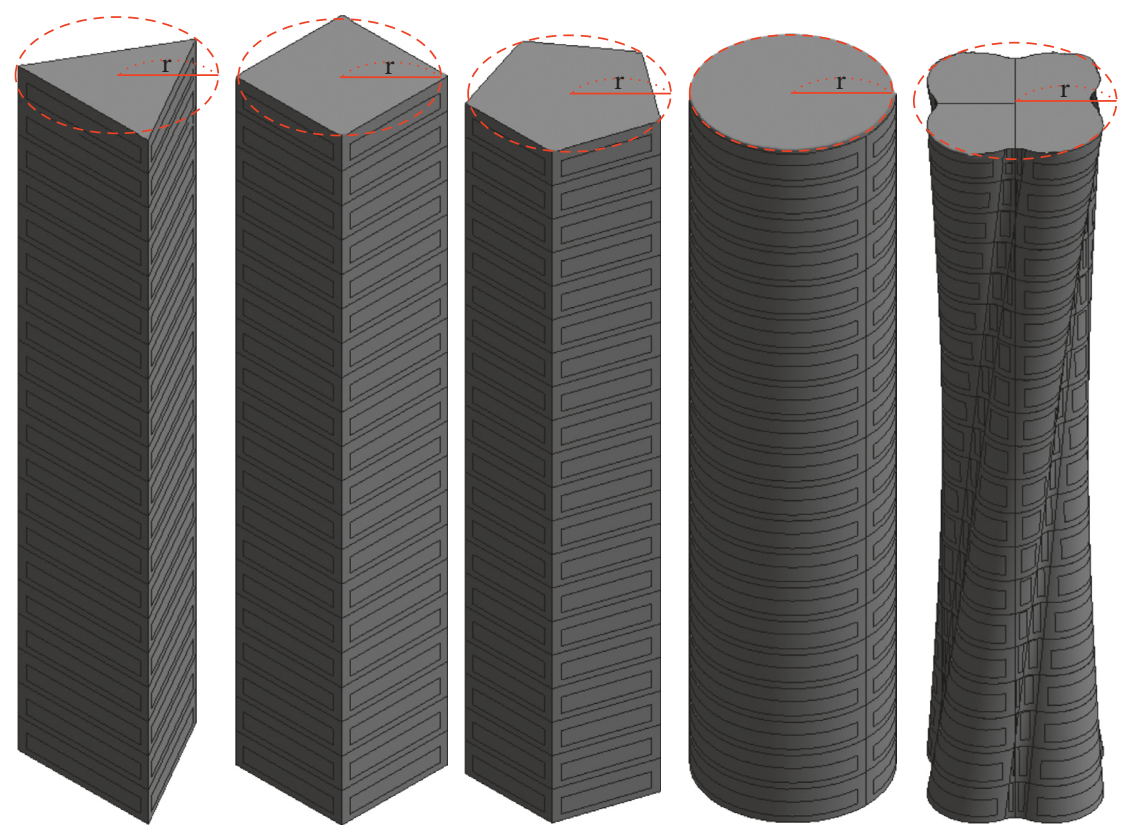

FIGURE 2: Energy model for analysis of form and window area ratio using BIM.

3.2.1. Mass Form and Window Area Ratio. Mass form and window area ratio are architectural design elements that have the greatest impact on facades in mess design. Additionally, the window area greatly affects energy performance. Thus, this study aims to examine the correlation with energy performance by analyzing and comparing the window area ratio by mass form in the early design stage. Tower forms consist mainly of column mass vertically overlapping geometric planes such as circle, ellipse, and polygon.

Therefore, this study derived typical types such as triangle, quadrilateral, and pentagon as an alternative to mass form design for tower residential and business facilities. Moreover, the atypical types to compare with them were selected as the control group. On the basis of the assumption, this study changed the window area ratio from $10 \%$ to $90 \%$ according to changes in the form and scale of the tower mass for analysis as shown in Figure 2. Furthermore, in order to maintain the same mass ratio of long side to short side, the same distance from the center to the outer wall of the building was set so that each radius is inscribed in $10 \mathrm{~m}$, $15 \mathrm{~m}$, and $20 \mathrm{~m}$ circles.

3.2.2. Window Area Ratio and Floor Height. With regard to the mass with the same total floor area in Figure 2, this study changed only floor height and window area ratio for analysis. The floor height and window area ratio of residential facilities were changed from $2.5 \mathrm{~m}$ to $4.0 \mathrm{~m}$ with reference to quadrilateral mass model, and those of business facilities were changed from $3.0 \mathrm{~m}$ to $4.5 \mathrm{~m}$. Additionally, only envelop area and volume increased without a change in floor area when changing the floor height, and this made it possible to understand the problems of the existing method for calculating energy consumption per floor area. Moreover, this makes it possible to specifically analyze the correlation of changes in envelope area and volume on energy consumption.

3.2.3. Window Area Ratio and Ratio of Long Side to Short Side. Recently, many square lots have appeared. Currently, however, the ratio of long side to short side of the standard plot in South Korea ranges from 0.75 to 1.9. The mean value is 1.2 , and the maximum value is less than 2.0 [7]. In addition, the scale of individual lot was less than $600 \mathrm{~m}^{2}$, and the ratio of long side to short side was less than $1: 2$. Normally, scale and form of lots directly affect mass form, but only this information makes it impossible to establish the premise that the ratio of long side to short side of building mass design does not exceed the ratio of $1: 2$. Therefore, this study aims to analyze and compare the energy consumption according to building plan elements such as the building direction, the window area ratio, and the ratio of long side to short side directly affected by solar energy as a building design element for energy saving in buildings [8]. This study analyzed the correlation between design methods and energy performance based on the values analyzed by varying the window area ratio depending on the design form, scale, and ratio of long side to short side of tower mass [9].

As shown in Figure 3, the quadrilateral mass is set southward. In general buildings, the ratio of long side to short side does not exceed 1:3 due to site constraints [10]. However, because large-scale buildings are constructed by merging several lots into one lot and new lots are planned for landmark in new towns, this study modeled the ratio of long side to short side from $10: 1$ to $1: 10$ in tens of meters. This study aimed to derive the clear correlation between the ratio of long side to short side and energy performance based on the result and changed the window area ratio from $10 \%$ to $90 \%$ according to changes in the form and scale of the mass for analysis. 


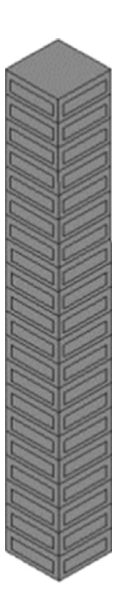

$1: 1$

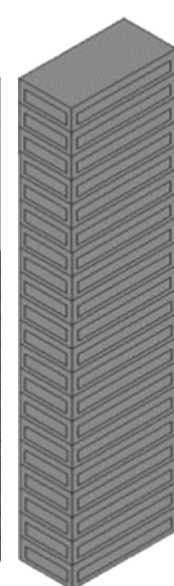

$1: 2$

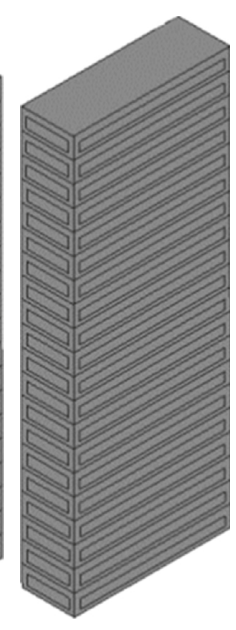

$1: 3$

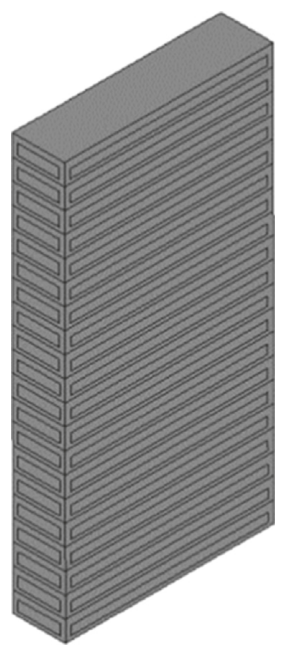

$1: 4$

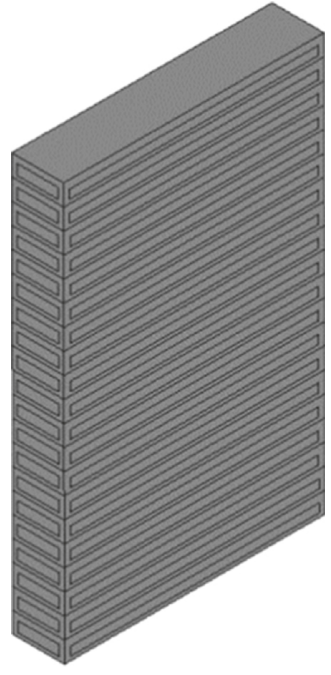

$1: 5$

FIGURE 3: Energy model for ratio of long side to short side analysis using BIM.

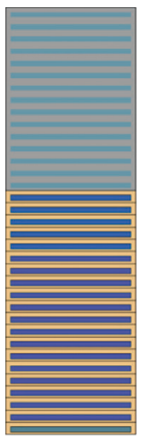

$-90^{\circ}$

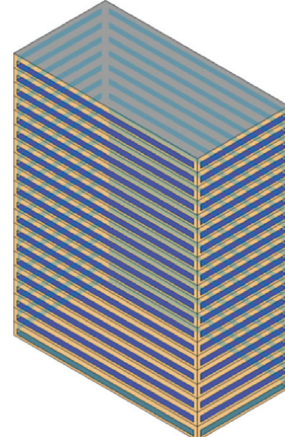

$-40^{\circ}$

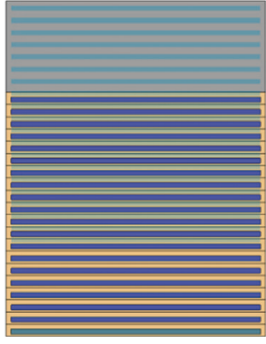

$0^{\circ}$
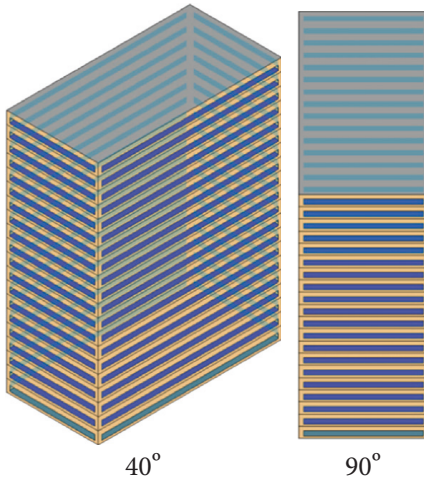

$90^{\circ}$

FIGURE 4: Energy model for analysis of direction using BIM.

3.2.4. An Analysis of Energy Consumption by Direction. As shown in Figure 4, it is considered that energy performance according to the ratio of long side to short side is related to the direction. For more accurate analysis, this study changed the direction of the mass with ratio of long side to short side of 1.0 to 3.0. The direction are based on $0^{\circ}$ (southward), and the experiment was performed by changing the direction from $-90^{\circ}$ (westward) to $+90^{\circ}$ (southward) at $10^{\circ}$ intervals. In this case, there may be a problem whether to set the different window area ratios by direction. However, because the experiments focused on mass towers and limited to the level in the early design stage, it was assumed that the window area ratio by direction was the same as the previous experiments. This study changed the window area ratio from $10 \%$ to $90 \%$ according to changes in the ratio of long side to short side and direction.

3.3. Outline of BIM Models. As shown in Tables 2 and 3 [3, 11], the BIM models located in Seoul have 20 stories and two building types such as residential and business facilities [12].
Building type, HVAC system, and others were set according to the experimental design [13].

\section{Results}

4.1. Window Area Ratio and Mass Form. This study performed energy performance analysis of residential and business facilities using the models with the same mass form. In addition, this study analyzed how building mass form affected energy performance of the tower type. Analysis items, such as tower type, window area ratio, envelope area, volume, and the total floor area derived at LOD 100 were set as a determinant. Table 4 shows the scale of the mass model used in the experiments.

As shown in Figures 5 and 6, with regard to all the towers, the envelope area, volume, and floor area increased twice, four times, and four times with radius from $10 \mathrm{~m}$ to $20 \mathrm{~m}$, respectively. Regarding the circle tower generally accepted as the most excellent energy performance, the energy consumption of residential facilities increased 3.2 times with the ratio of long side to short side of $90 \%$, 
TABLE 2: Building summary.

\begin{tabular}{lcc}
\hline Items & \multicolumn{1}{c}{ Description } \\
\hline $\begin{array}{l}\text { Building type } \\
\text { Location data (latitude/longitude/above sea } \\
\text { level) }\end{array}$ & Residential facilities & Business facilities \\
Weather data (type) & Seoul $(37.57 / 126.98 / 82 \mathrm{~m})$ & Seoul, Korea (EPW) \\
Height (story/floor height) & $80 \mathrm{~m}(20 \mathrm{~F} / 4 \mathrm{~m})$ & Office-open plan \\
$\begin{array}{l}\text { Space type } \\
\text { Condition type }\end{array}$ & Apartment & Heated and cooled \\
HVAC system & Residential 17 SEER/9.6 HSPF split Central VAV, HW heat, chiller 5.96 COP, \\
\hline
\end{tabular}

increased up to 3.8 times with the ratio of long side to short side of $10 \%$, and increased 3.5 times on average. Moreover, the energy consumption of business facilities increased 2.6 times with the ratio of long side to short side of $90 \%$, increased up to 3.5 times with the ratio of long side to short side of $10 \%$, and increased 2.9 times on average. Furthermore, with the triangle tower regarded as the lowest energy performance, the energy consumption of residential facilities increased 3.0 times with the ratio of long side to short side of $90 \%$, increased up to 3.6 times with the ratio of long side to short side of $10 \%$, and increased 3.1 times on average. The energy consumption of business facilities increased 2.4 times with the ratio of long side to short side of $90 \%$, increased up to 2.9 times with the ratio of long side to short side of $10 \%$, and increased 2.5 times on average.

These increases make it difficult to understand the precise hierarchy except for the fact that energy consumption increases in proportion to the window area ratio.

Thus, this study divided energy consumption into each envelope area, volume, and floor area. As a result, the energy consumption increases in proportion to the window area ratio and envelope area regardless of the type or scale of mass as shown in Figures 7 and 8. Moreover, it was not possible to find a clear correlation between the floor area and energy consumption as well as between the volume and energy consumption.

4.2. Window Area Ratio and Floor Height. This study analyzed energy consumption with changes in floor height based on the hierarchy according to the correlation between window area ratio and mass form. For the analysis, the floor height of residential facilities were changed from $2.5 \mathrm{~m}$ to $4.0 \mathrm{~m}$, and those of business facilities were changed from $3.0 \mathrm{~m}$ to $4.5 \mathrm{~m}$ in increments of $0.1 \mathrm{~m}$ with reference to the existing mass model with a floor height of $4 \mathrm{~m}$. Only envelope area and volume increased without a change in floor area when changing the floor height, and changes in energy performance were analyzed without changes in the floor area in the experiments.

As a result of the experiments, envelope area and window area ratio were proportional to energy consumption. The energy consumption of residential facilities
Table 3: Predetermined values of the energy model.

\begin{tabular}{|c|c|c|c|}
\hline Mass model & \multicolumn{3}{|c|}{$U$ value $\left(\mathrm{W} / \mathrm{m}^{2} \cdot{ }^{\circ} \mathrm{K}\right)$} \\
\hline Exterior wall & \multicolumn{3}{|l|}{0.58} \\
\hline Interior wall & \multicolumn{3}{|l|}{4.17} \\
\hline Exterior wall underground & \multicolumn{3}{|l|}{0.52} \\
\hline Roof & \multicolumn{3}{|l|}{0.26} \\
\hline Floor & \multicolumn{3}{|l|}{0.27} \\
\hline \multirow[t]{2}{*}{ Slab } & \multicolumn{3}{|l|}{0.93} \\
\hline & $U$ value $\left(\mathrm{W} / \mathrm{m}^{2} \cdot{ }^{\circ} \mathrm{K}\right)$ & SHGC & Tvis \\
\hline Glazing & 0.10 & 0.69 & 0.78 \\
\hline Skylight & 0.10 & 0.69 & 0.78 \\
\hline
\end{tabular}

TABLE 4: Scale arrangements depending on forms of tower.

\begin{tabular}{lcccc}
\hline \multirow{2}{*}{ Classification } & & \multicolumn{3}{c}{ Radius $(r)$} \\
& & $10 \mathrm{~m}$ & $15 \mathrm{~m}$ & $20 \mathrm{~m}$ \\
\hline \multirow{4}{*}{ Triangular } & External area $\left(\mathrm{m}^{2}\right)$ & 4157 & 6235 & 8314 \\
& Volume $\left(\mathrm{m}^{3}\right)$ & 10,392 & 23,384 & 41,568 \\
& Floor space $\left(\mathrm{m}^{2}\right)$ & 2598 & 5846 & 10,392 \\
& External area $\left(\mathrm{m}^{2}\right)$ & 4525 & 6788 & 9051 \\
Rectangular & Volume $\left(\mathrm{m}^{3}\right)$ & 16,000 & 36,000 & 64,000 \\
& Floor space $\left(\mathrm{m}^{2}\right)$ & 4000 & 9000 & 16,000 \\
Pentagon & External area $\left(\mathrm{m}^{2}\right)$ & 4702 & 7053 & 9405 \\
& Volume $\left(\mathrm{m}^{3}\right)$ & 19,020 & 42,796 & 76,084 \\
& Floor space $\left(\mathrm{m}^{2}\right)$ & 4755 & 10,699 & 19,021 \\
Circular & External area $\left(\mathrm{m}^{2}\right)$ & 5027 & 7540 & 10053 \\
& Volume $\left(\mathrm{m}^{3}\right)$ & 25,128 & 56,540 & 100,520 \\
& Floor space $\left(\mathrm{m}^{2}\right)$ & 6282 & 14,135 & 25,130 \\
Free form & External area $\left(\mathrm{m}^{2}\right)$ & 3980 & 5998 & 8050 \\
& Volume $\left(\mathrm{m}^{3}\right)$ & 13,800 & 31,048 & 55,204 \\
& Floor space $\left(\mathrm{m}^{2}\right)$ & 3450 & 7762 & 13,801 \\
\hline
\end{tabular}

changed from $5.9 \%$ to $11.8 \%$ with a change in the floor height of $1 \mathrm{~m}$ and varied by $8.0 \%$ on average. It had less impact on energy consumption compared to envelope area. However, the energy consumption of business facilities changed from $17.1 \%$ to $20.8 \%$ and varied by $19.0 \%$ on average. It had a greater impact on energy consumption compared to residential facilities. 


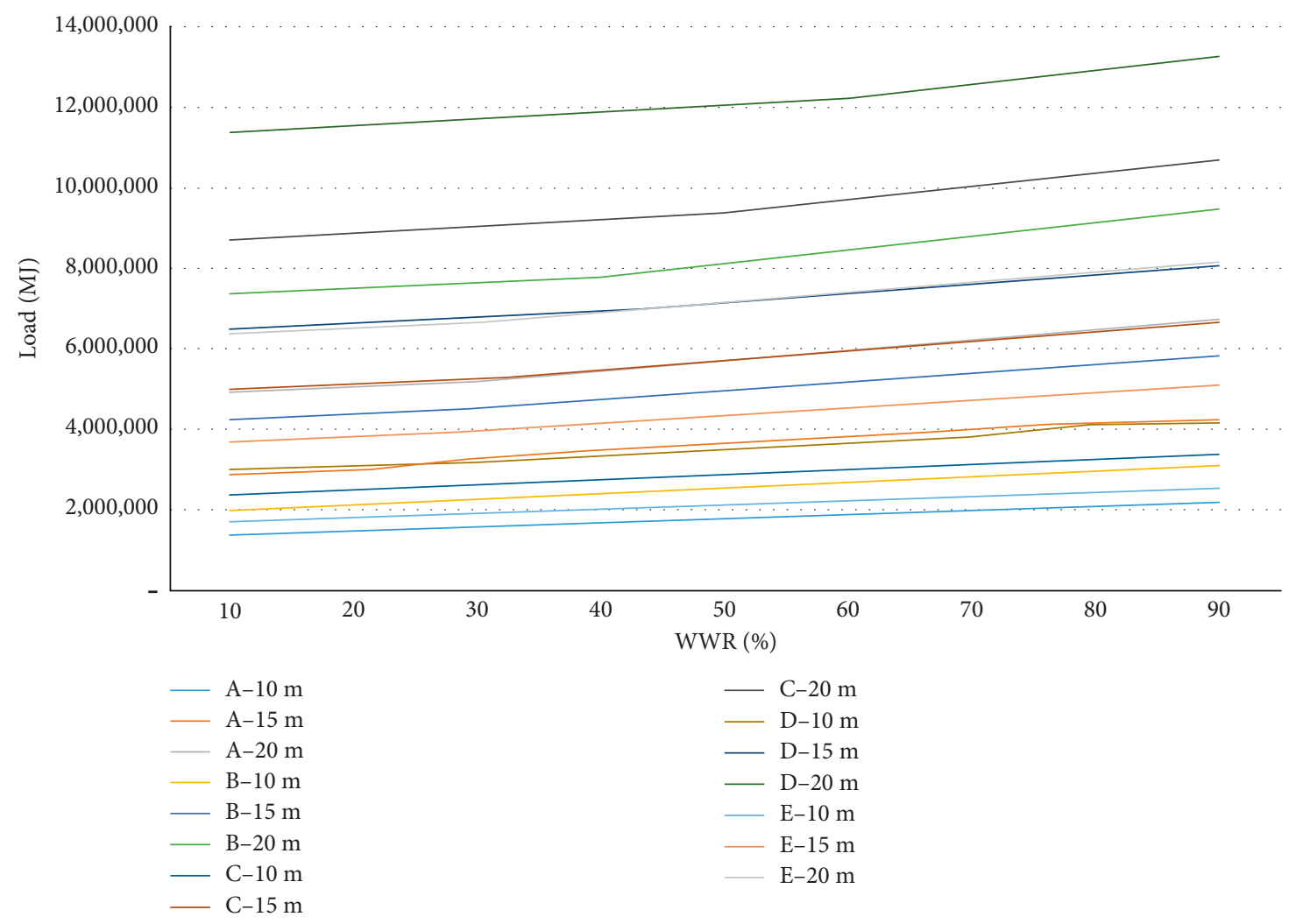

FIGURE 5: Energy consumption by tower type and size (MJ): residential facilities.

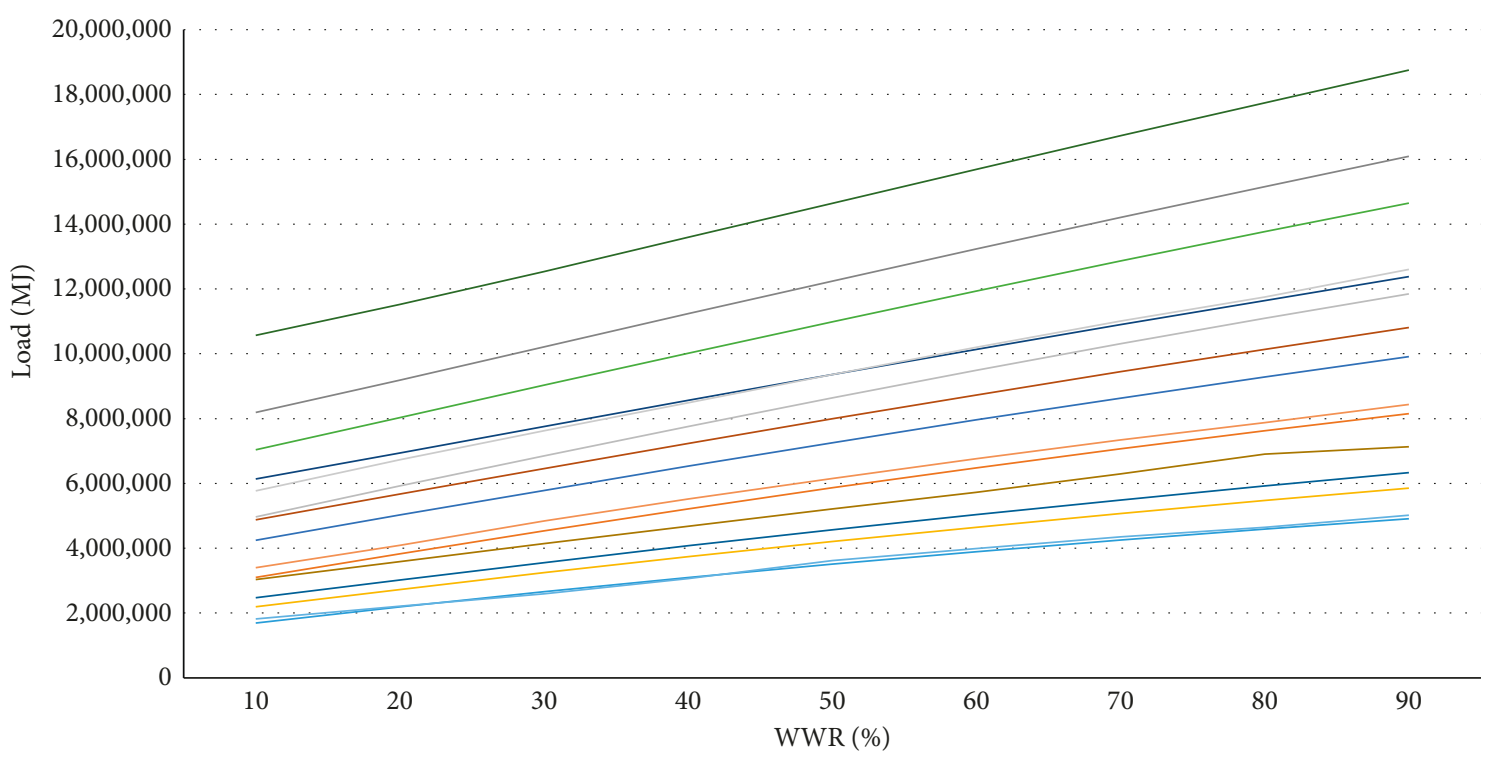
- A-10 m
- A-15 m
A-20 m
B-10 m
- B-15 m
- B-20 m
- C-10 m
C-15 m

- C $-20 \mathrm{~m}$

- D-10 m
- D-15 m
D-20 m
E-10 m
E-15 m
E-20 m

Figure 6: Energy consumption by tower type and size (MJ): business facilities. 


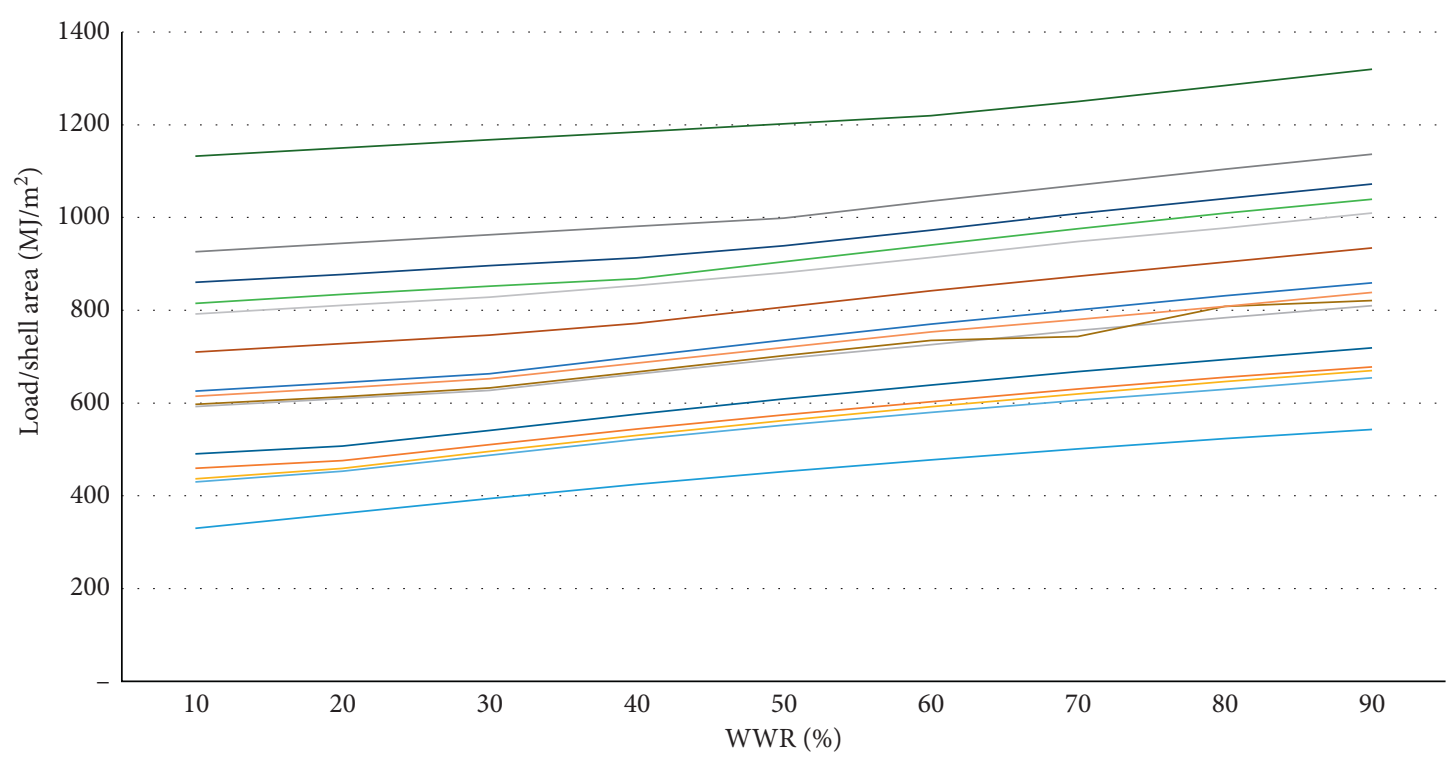

A-10 m
- A-15 m
A-20 m
B-10 m
- B-15 m
- B-20 m
- C-10 m
- C-15 m

- C $-20 \mathrm{~m}$

- D-10 m

D-15 m

D-20 m

- E-10 m

- E-15 m

FIGURE 7: Energy consumption per shell area by tower type and scale $\left(\mathrm{MJ} / \mathrm{m}^{2}\right)$ : residential facilities.

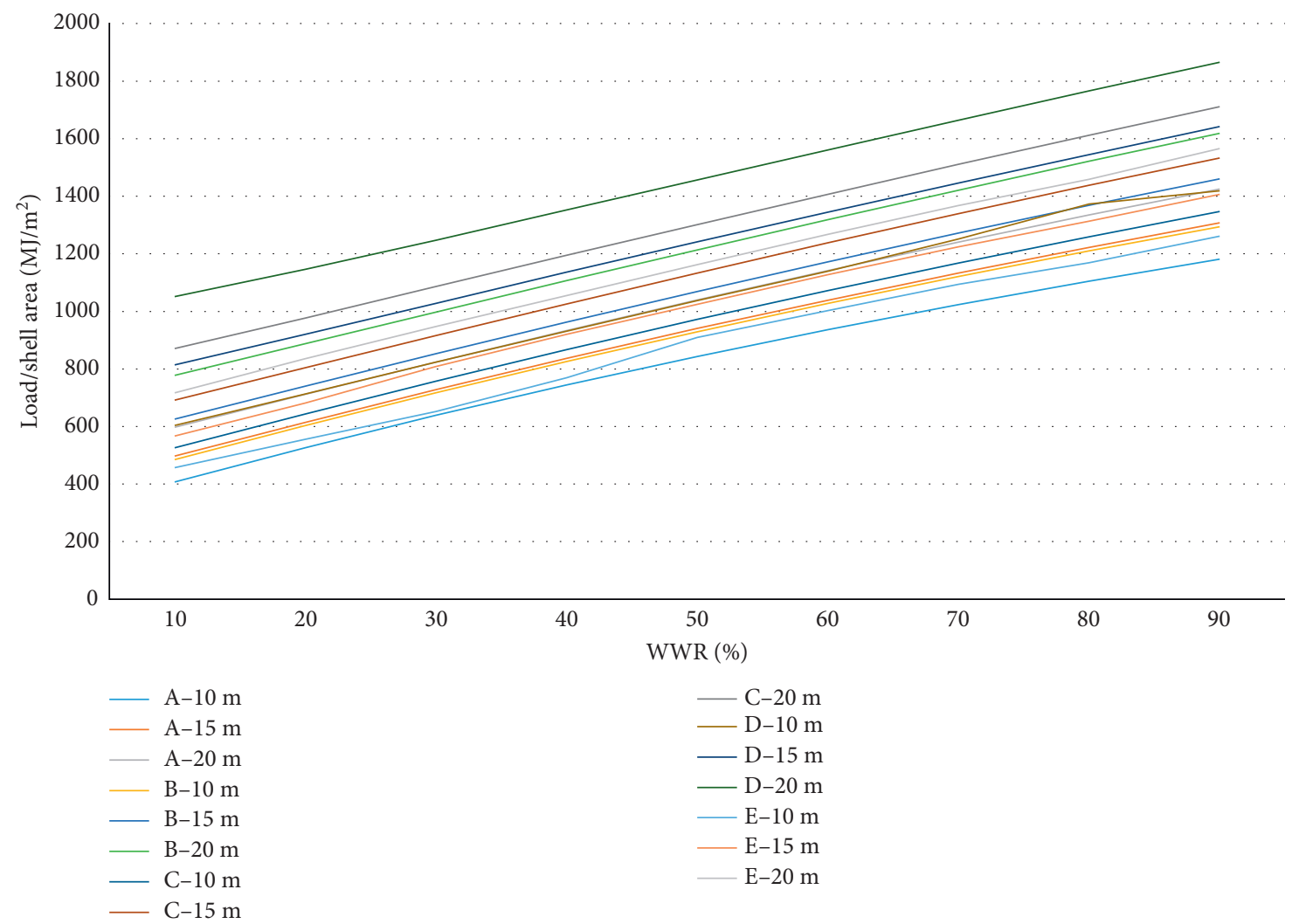

FIGURE 8: Energy consumption per shell area by tower type and scale $\left(\mathrm{MJ} / \mathrm{m}^{2}\right)$ : business facilities. 
4.3. Window Area Ratio and Ratio of Long Side to Short Side. Although previous experiments were performed on tower buildings with the ratio of long side to short side of 1 : 1 , this study analyzed the hierarchy how the ratio of long side to short side of buildings changes in the scale and energy consumption were correlated in this experiment. As shown in Figures 9-11, this study analyzed and compared the mass extending east and west and north and south with ratio and ratio of long side to short side from $10: 1$ to $1: 10$ by changing the horizontal and vertical lengths and width of tower buildings from $10 \mathrm{~m}$ to $100 \mathrm{~m}$ in tens of meters.

These experiments were conducted to analyze changes in energy consumption by the ratio of long side to short side. As a result of the comparison of the mass extending east and west with the ratio of $10: 1$ and north and south with the ratio of $1: 10$, the mass extending east and west showed higher energy consumption than that extending north and south. In addition, the energy consumption per floor area of residential and business facilities showed the smallest difference of $1.3 \%$ with the ratio of long side to short side of $10 \%$ and the greatest difference of $9.3 \%$ with the window area ratio of $90 \%$. The average deviation was $6.2 \%$.

For instance, mass with the window area ratio of $40 \%$ and with height and width of " $10 \mathrm{~m} \times 50 \mathrm{~m}$ " and " $20 \mathrm{~m} \times 100 \mathrm{~m}$ " showed the same ratio of long side to short side of 1:5, but the differences between mass extending east and west and north and south were $5.9 \%$ and $4.9 \%$, respectively. They did not directly affect the ratio of long side to short side. Additionally, the differences decreased with increasing mass scale. Figure 12 shows the schematization of energy consumption with the window area ratio of $40 \%$. A curve appears on the graph when the ratio of long side to short side increased to the directions from $1: 1,1: 10$, and 10 $: 1$. It is considered that this curve has "envelope area $\left(\mathrm{m}^{2}\right)=$ circumference of standard floor $(\mathrm{m}) \times$ height $(\mathrm{m})$ " and is affected by the circumference of the standard floor. However, the mass with "height and width" of " $100 \mathrm{~m} \times 20 \mathrm{~m}$ " and " $20 \mathrm{~m} \times 100 \mathrm{~m}$ " has the same scale and circumference of the standard floor except for the fact that each mass was placed in the north-south direction and eastwest direction, respectively.

4.4. Window Area Ratio and Direction. Energy consumption did now show a direct correlation with the ratio of long side to short side in the experiment of the window area ratio and ratio of long side to short side. It is estimated that the difference in energy consumption was affected by the direction. Although it is an item in the low hierarchy, this study analyzed energy consumption by limiting the ratio of long side to short side to $1: 1,1: 1.5,1: 2$, and $1: 3$ and changing the direction for each tower building from $+90^{\circ}$ (eastward) to $-90^{\circ}$ (westward) at $10^{\circ}$ intervals with reference to southward $\left(0^{\circ}\right)$. In this case, the rate of change according to the window area ratio with reference to southward before considering the direction is shown in Table 5. Although the increase rate of energy consumption decreased with increasing the window area ratio, there was a constant decrease

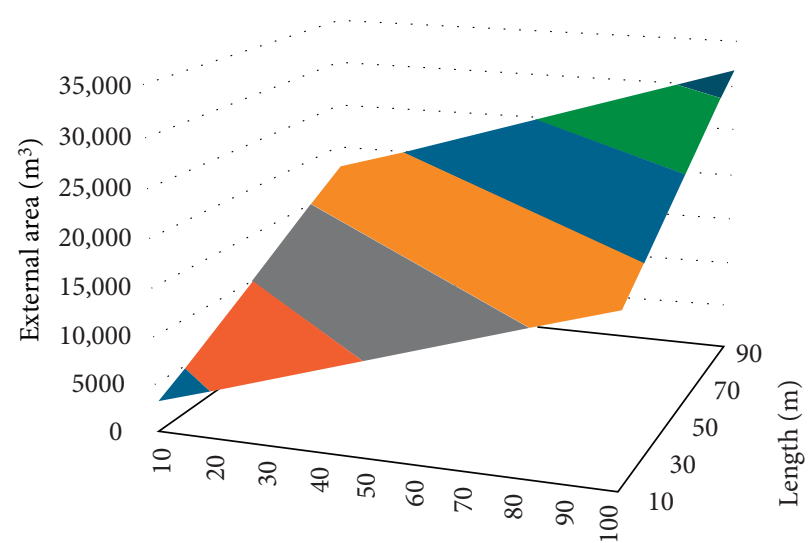

Width (m)

$$
\begin{aligned}
& \text { - 30,000-35,000 10,000-15,000 } \\
& \text { - 25,000-30,000 - 5000-10,000 } \\
& \text { — 20,000-25,000 — } 0-5000 \\
& \text { - 15,000-20,000 }
\end{aligned}
$$

FIGURE 9: Changes in physical properties according to mass scale: envelope area $\left(\mathrm{m}^{2}\right)$.

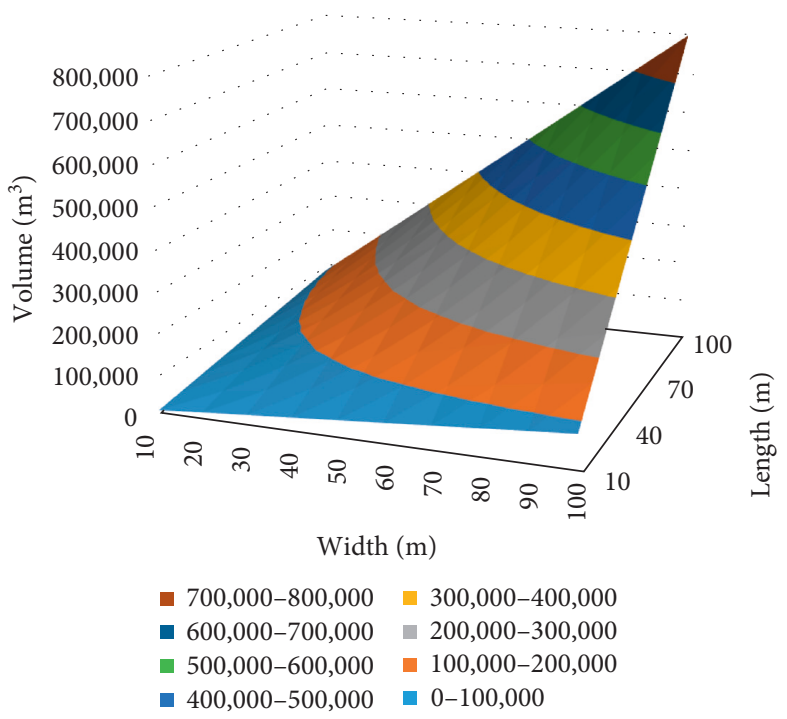

FIGURE 10: Changes in physical properties according to mass scale: volume $\left(\mathrm{m}^{3}\right)$.

without greatly affecting the ratio of long side to short side. Energy consumption was proportional to the window area ratio.

As shown in the $30 \mathrm{~m} \times 10 \mathrm{~m}$ tower building in Figure 13 , it showed the smallest energy consumption within $\pm 10^{\circ}$ with reference to $0^{\circ}$ and the highest energy consumption from $50^{\circ}$ to $70^{\circ}$. Moreover, the increase rate of energy consumption relatively constantly decreased with increasing window area ratio, and the rate of change in energy consumption to the direction increased with increasing window area ratio. The directional difference was the smallest with the ratio of long side to short side of $1: 1$ and the largest with the ratio of long side to short side of $1: 3$. The deviation 


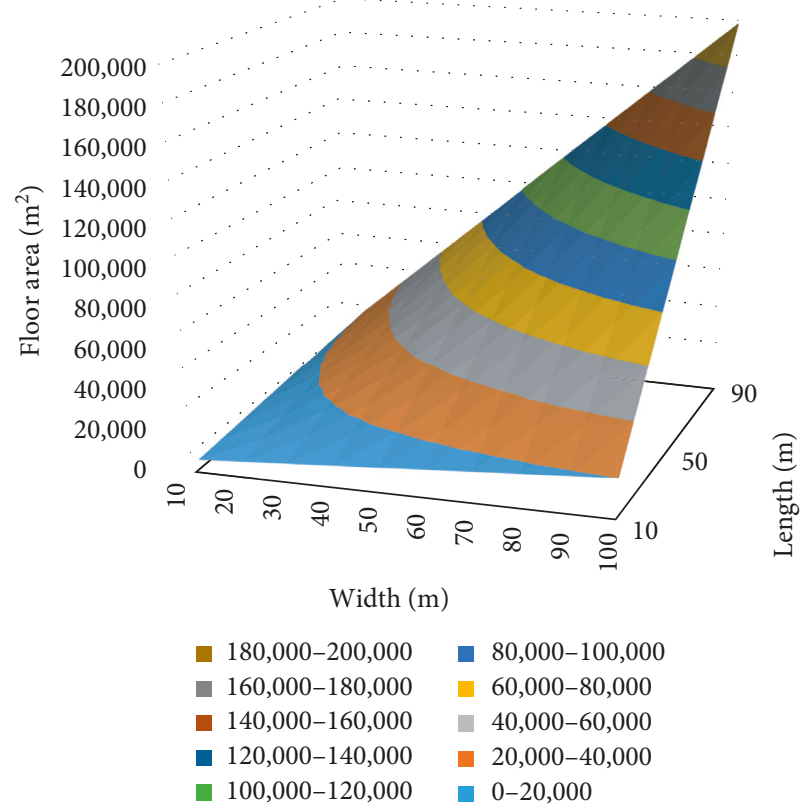

FIGURE 11: Changes in physical properties according to mass scale: floor area $\left(\mathrm{m}^{2}\right)$.

percentage gradually increased with the window area ratio and with increasing ratio of long side to short side. Furthermore, there was a slight difference in energy consumption to the direction ranged from $0.35 \%$ to $0.87 \%$ when the ratio of long side to short side was $1: 1$. Conversely, it increased from $3.21 \%$ to $5.55 \%$ with the ratio of long side to short side of $1: 3$.

However, when the difference in energy requirement is divided by the area ratio, the rate of energy change with respect to the area ratio is $0.035 \sim 0.087$ when the window area ratio is $10 \%$ and $0.036 \sim 0.062$ when the window area ratio is $90 \%$. In other words, it is judged that the window area ratio does not have an effect on the energy performance according to the incense in the building.

In this experiment, the direction was the lowest in the hierarchy, and the rate of change in energy consumption was also the lowest. However, it is considered that the hierarchy of the direction was the lowest because the same window area ratio of the tower mass was set to the four sides. Therefore, in order to compensate for this weakness, there is a need for an analysis applying different window area ratios by direction in energy performance analysis using BIMbased energy models at more than LOD 200 according to the design process in the future. Especially in South Korea, it is considered possible to maximize the energy efficiency by setting appropriate window area ratio by direction based on design because buildings are greatly affected by monsoon due to distinct seasons.

Nevertheless, because solar irradiance through windows increases with increasing window area ratio, energy consumption increased according to the direction. Window area ratio was proportional to energy consumption regardless of direction.

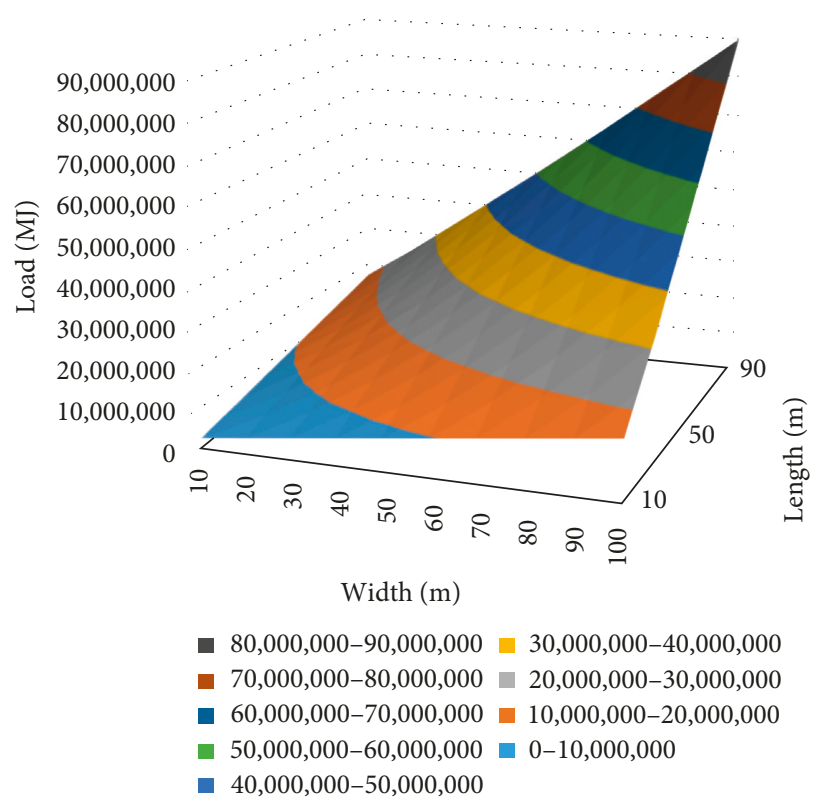

FIGURE 12: Energy consumption by mass scale (window area ratio $40 \%, \mathrm{MJ})$.

\section{Discussion}

The analysis made it possible to examine important design methods for planning tower apartment residential facilities and tower business facilities. First, the hierarchy shown in Table 6 can be set. With regard to residential facilities, it is most important to reduce an envelope area in mass design, and then there is a need to consider volume and floor area at the same time. Important elements were floor height, window area ratio, and the ratio of long side to short side, in that order. However, the rate of change by envelope area was relatively high and showed overwhelming values compared to other architectural design elements. In particular, the envelope area in residential facilities showed $42.5 \%$ of influence when representing the influence only by architectural design elements affecting the energy consumption shown in Table 7 and Figure 14 and made it possible to examine the importance of reducing an envelope area in planning residential facilities compared to that in business facilities of $17.1 \%$. Moreover, the window area ratio showed $5.3 \%$ of influence per $10 \%$ and had a small impact differently from that of the previous thought that it was very advantageous to reduce the size of windows in general residential planning. This enabled us to understand the difference in design methods in considering energy performance [14].

The same holds true for business facilities. It was considered the most advantageous to reduce an envelope area to reduce a window area ratio and to place southward from the perspective of energy performance in the previous approaching method from specific architectural theories. However, according to the results, it is most important to lower floor height relatively freely planned thus far; floor area, floor, and envelope area have a similar hierarchy. With 
TABle 5: Changes in energy expenditure per unit area due to ratio of long side to short side and window area ratio (\%).

\begin{tabular}{|c|c|c|c|c|c|c|c|c|}
\hline $\begin{array}{l}\text { Scale } \\
\text { Ratio of long side to short side }\end{array}$ & $\begin{array}{c}30 \times 10 \\
3: 1\end{array}$ & $\begin{array}{c}20 \times 10 \\
2: 1\end{array}$ & $\begin{array}{l}30 \times 20 \\
1.5: 1 \\
\end{array}$ & $\begin{aligned} 20 & \times 20 \\
1 & : 1\end{aligned}$ & $\begin{array}{c}20 \times 30 \\
1: 1.5\end{array}$ & $\begin{aligned} 10 & \times 20 \\
1 & : 2\end{aligned}$ & $\begin{array}{l}10 \times 30 \\
1: 3\end{array}$ & Average \\
\hline $10 \sim 20 \%$ & 28.0 & 29.4 & 20.6 & 23.3 & 20.6 & 29.4 & 28.0 & 25.6 \\
\hline $20 \sim 30 \%$ & 21.0 & 21.6 & 16.8 & 18.5 & 16.8 & 21.6 & 21.0 & 19.6 \\
\hline $30 \sim 40 \%$ & 16.5 & 16.8 & 14.0 & 15.1 & 14.0 & 16.8 & 16.5 & 15.7 \\
\hline $40 \sim 50 \%$ & 13.4 & 13.6 & 11.9 & 12.6 & 11.9 & 13.6 & 13.4 & 12.9 \\
\hline $50 \sim 60 \%$ & 11.2 & 11.3 & 10.3 & 10.7 & 10.3 & 11.3 & 11.2 & 10.9 \\
\hline $60 \sim 70 \%$ & 9.6 & 9.6 & 9.0 & 9.3 & 9.0 & 9.6 & 9.6 & 9.4 \\
\hline $70 \sim 80 \%$ & 8.3 & 8.3 & 8.0 & 8.1 & 8.0 & 8.3 & 8.3 & 8.2 \\
\hline $80 \sim 90 \%$ & 7.3 & 7.2 & 7.1 & 7.2 & 7.1 & 7.2 & 7.3 & 7.2 \\
\hline $10 \sim 90 \%$ & 189.2 & 195.5 & 149.9 & 165.5 & 149.8 & 195.4 & 189.0 & 176.3 \\
\hline
\end{tabular}

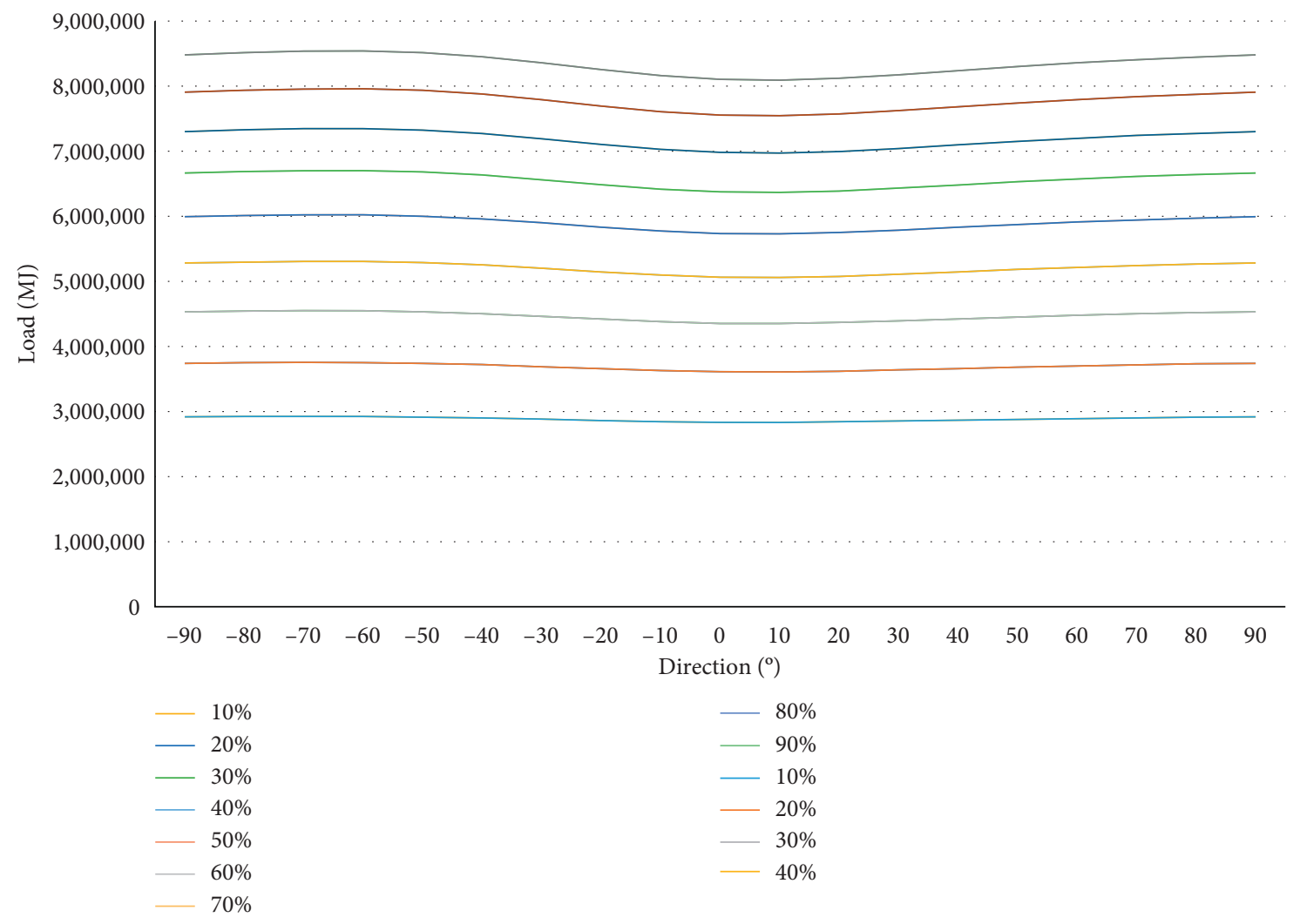

Figure 13: Energy consumption due to changes in tower incense and window area ratio (MJ).

TABLE 6: Rate of change of energy requirement by architectural design element (\%).

\begin{tabular}{lccccccc}
\hline & Envelope area & Floor area & Volume & Floor height & Window area ratio & Ratio of long side to short side & Direction \\
\hline Residential facilities & 28.5 & 3.4 & 8.0 & 6.2 & 9.1 & 9.1 & 2.7 \\
Business facilities & 15.4 & 10.4 & 19.0 & 6.2 & 18.2 & 18.2 & 2.7 \\
\hline
\end{tabular}

TABLE 7: Rate of transformation influenced by hierarchy by architectural design elements (\%).

\begin{tabular}{lccccccc}
\hline & Envelope area & Floor area & Volume & Floor height & Window area ratio & Ratio of long side to short side & Direction \\
\hline Residential facilities & 42.5 & 13.6 & 13.6 & 11.9 & 5.1 & 9.3 & 4.0 \\
Business facilities & 17.1 & 20.2 & 20.2 & 21.1 & 11.5 & 6.9 & 3.0 \\
\hline
\end{tabular}




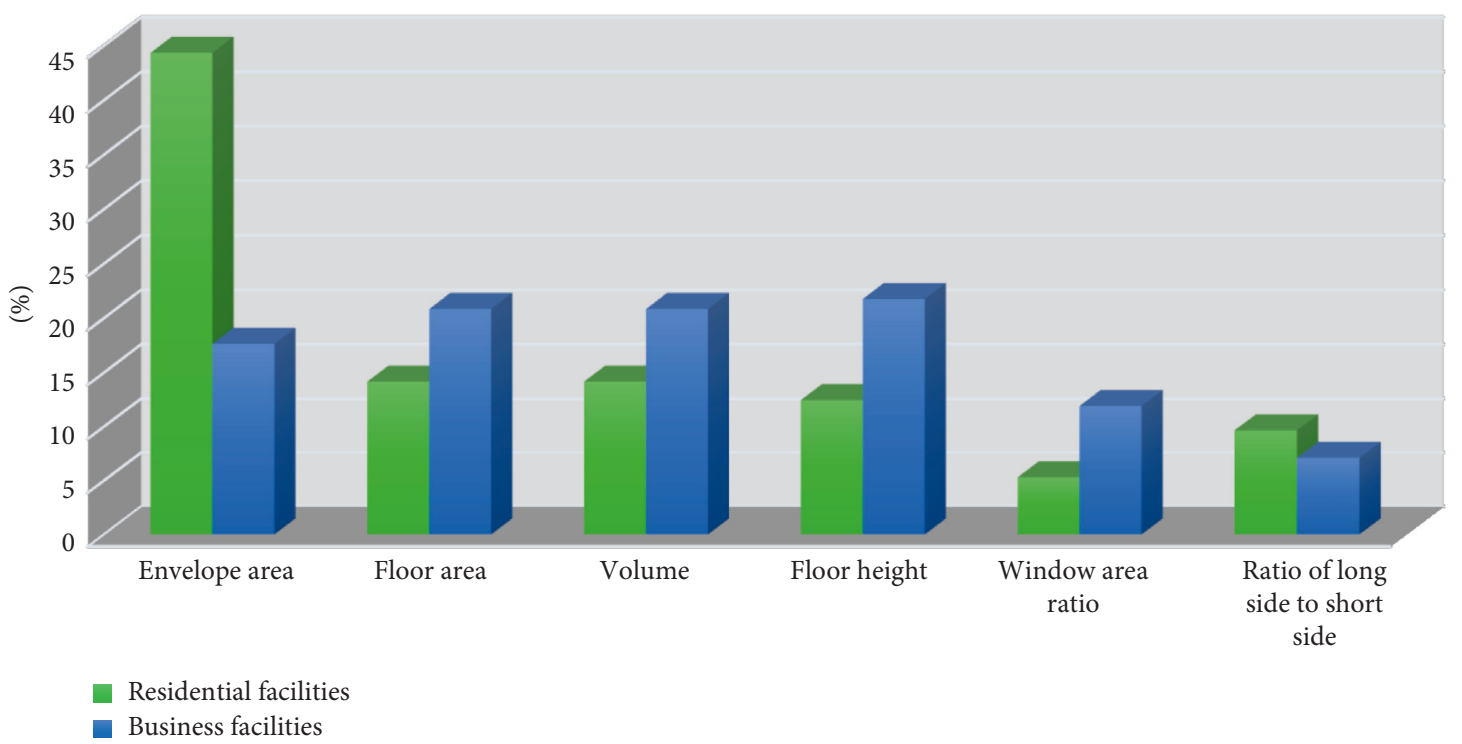

FIGURE 14: Rate of transformation influenced by hierarchy by architectural design elements (\%).

regard to energy performance in architectural planning, residential and business facilities have been designed by the same or similar methods thus far [15]. However, as shown in this experiment, it is necessary to individually develop energy performance-based design methods for different two types of buildings.

\section{Conclusions}

The core of energy performance-based design that this study aims to analyze is to plan energy performance-based design based on energy requirement excluding the HVAC system. As a result, the energy performance according to changes in the window area ratio increased up to 2.9 times on average and greatly exceeds the "error range ranging from $10 \%$ to $30 \%$ in energy performance analysis by energy simulation" [16].

Thus, it is possible to save approximately $15 \%$ to $30 \%$ of energy consumption costs by the high-efficiency HVAC system even considering that there is a difference in performance analysis values depending on the building use schedule and HVAC system [17]. This makes it possible to realize the need to develop energy performancebased design methods based on pure building energy requirement.

Therefore, this study is significant in that it is possible to consider energy performance in determining the mass form in the early design stage to reduce opportunity costs by minimizing design revision with the development of design stages and to improve design quality.

Moreover, latitude, longitude, and meters above sea level in Seoul are different from those in other large cities worldwide. Thus, it is considered that the energy performance hierarchy for each architectural design element will be different. Therefore, it is thought necessary to analyze hierarchy for many more cities to establish a theory more accurately for this study.

\section{Conflicts of Interest}

The authors declare that they have no conflicts of interest.

\section{Acknowledgments}

This study was supported by the National Research Foundation of Korea (NRF-2017R1C1B2011983).

\section{References}

[1] Ministry of Land, Infrastructure and Transport, "G-SEED, notice of the Ministry of Land, Infrastructure and Transport no. 2013-383," 2013.

[2] K. H. Lee, I. H. Kim, and S. Y. Choo, "Model study of design components for energy performance based architectural design using BIM LOD 100," Journal of Green Building, vol. 10, no. 2, pp. 179-197, 2015.

[3] ASHRAE, ASHRAE Handbook Fundamentals, American Society of Heating, Refrigerating and Air-Conditioning Engineers, Inc., New Delhi, India, 2009.

[4] K. H. Lee, J. R. Ryu, and S. Y. Choo, "A correlation analysis on 'cooling and heating loads' and 'window to wall ratios' in accordance with the form of simulation-based office towersfocused on BIM model at the early design stages," Journal of the Architectural Institute of Korea, Planning \& Design, vol. 29, no. 9, pp. 15-24, 2013.

[5] AIA, AIA Document G203 ${ }^{\mathrm{TM}}-2013$, AIA, Washington, DC, USA, 2013.

[6] K. H. Lee, S. Y. Choo, and S. K. Park, "A study on LOD (level of development) for development of green BIM guidelinesfocused on energy performance estimation," Journal of the Architectural Institute of Korea, Planning \& Design, vol. 28, no. 6, pp. 34-47, 2012.

[7] K. H. Lee, I. H. Kim, and S. Y. Choo, "A study on improvement of energy performance index in green building certification system using BIM," Journal of the Architectural Institute of Korea, Planning \& Design, vol. 27, no. 9, pp. 13-21, 2011. 
[8] J. S. Cho, B. H. Lee, and Y. H. Yeo, "A comparative analysis of high-rise residential building forms based on ecology," Journal of the Architectural Institute of Korea, Planning \& Design, vol. 24, no. 2, pp. 31-41, 2008.

[9] K. H. Lee, I. H. Kim, and S. Y. Choo, "A causality analysis among architectural design decision factors in the early design stage-focused on reduction of cooling and heating loads in energy BIM simulation," Journal of the Architectural Institute of Korea, Planning \& Design, vol. 30, no. 12, pp. 31-39, 2014.

[10] Y. J. Lee, K. H. Lee, I. H. Kim, and S. Y. Choo, “A study on domestic standard parameter setting for BIM-based energy performance evaluation-focused on possession area per person of occupants in government offices," Korean Journal of Computational Design and Engineering, vol. 20, no. 1, pp. 11-21, 2015.

[11] Ministry of Land, Infrastructure and Transport, "Building energy efficiency rating system, notice of the Ministry of Land, Infrastructure and Transport no. 2015-1019," 2015.

[12] Ministry of Land, Infrastructure and Transport, "Building energy-saving design criteria, notice of the Ministry of Land, Infrastructure and Transport no. 2015-1108," 2015.

[13] Ministry of Land, Infrastructure and Transport, "Standards for the building energy efficiency rating system, ordinance of the Ministry of Land, Infrastructure and Transport no. 250," 2015.

[14] Y. S. Yoon, S. H. Mun, J. H. Yoon et al., "A study of correlation between window to floor ratio and building energy in curtain wall buildings," Journal of the Architectural Institute of Korea, Planning \& Design, vol. 28, no. 3, pp. 143-250, 2012.

[15] K. U. Ahn, Y. J. Kim, and C. S. Park, "Issues on dynamic building energy performance assessment in design process," Journal of the Architectural Institute of Korea, Planning \& Design, vol. 28, no. 12, pp. 361-369, 2012.

[16] S. Y. Song, B. K. Koo, and J. H. Lim, "Comparison of annual heating and cooling energy demands of internally and externally insulated apartment buildings considering the thermal bridging effect and the heat capacity difference using monthly calculation method of ISO 13790," Journal of the Architectural Institute of Korea, Planning \& Design, vol. 26, no. 7, pp. 321-332, 2010.

[17] D. W. Yeom and K. I. Lee, "Study on the Improvement of G-SEED management system," Journal of the Architectural Institute of Korea, Planning \& Design, vol. 31, no. 3, pp. 13-22, 2015. 


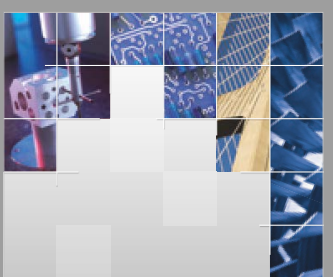

\section{Enfincering}
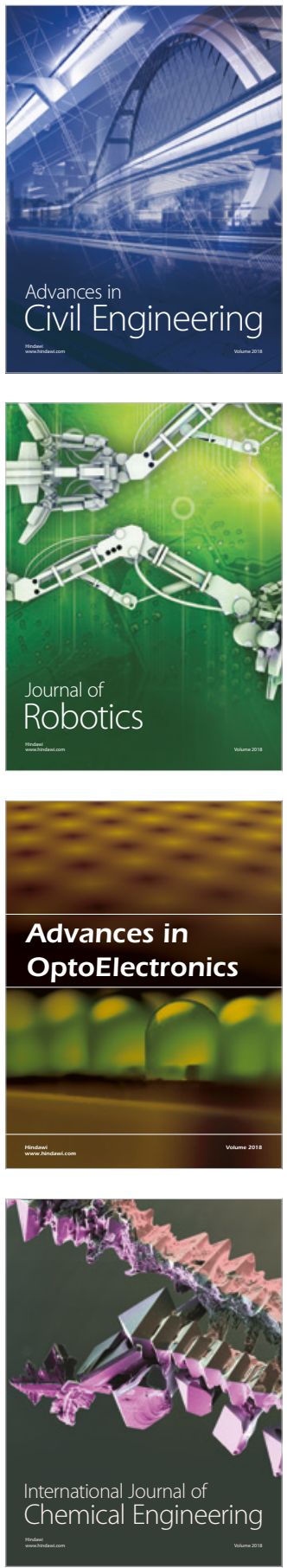

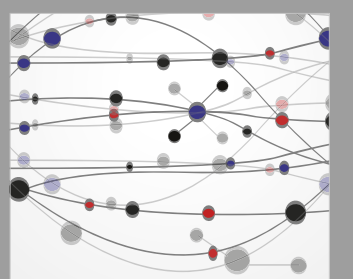

\section{Rotating \\ Machinery}

The Scientific World Journal

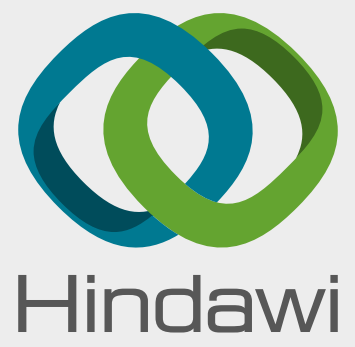

Submit your manuscripts at

www.hindawi.com
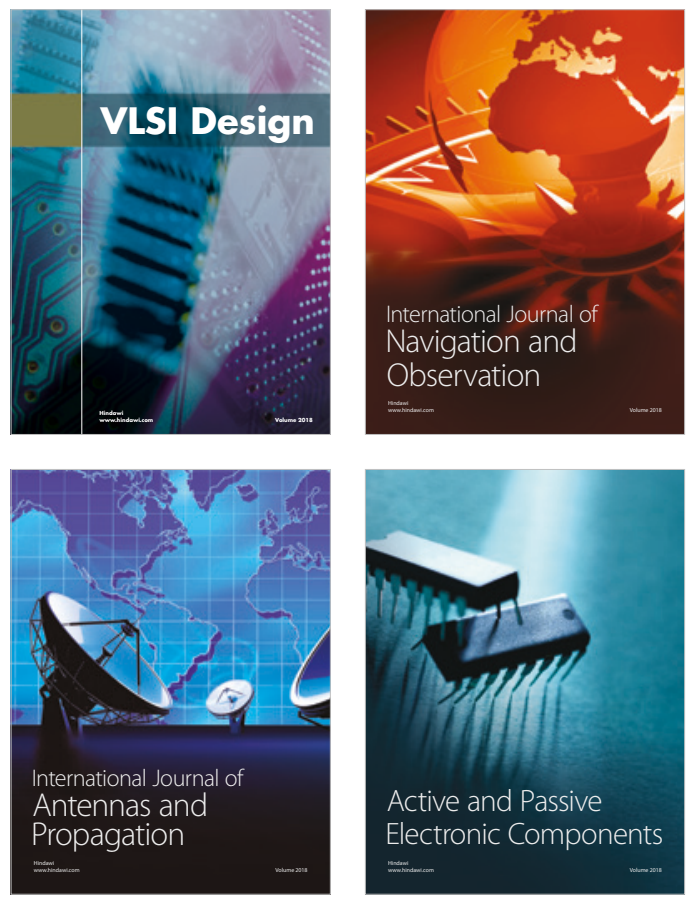
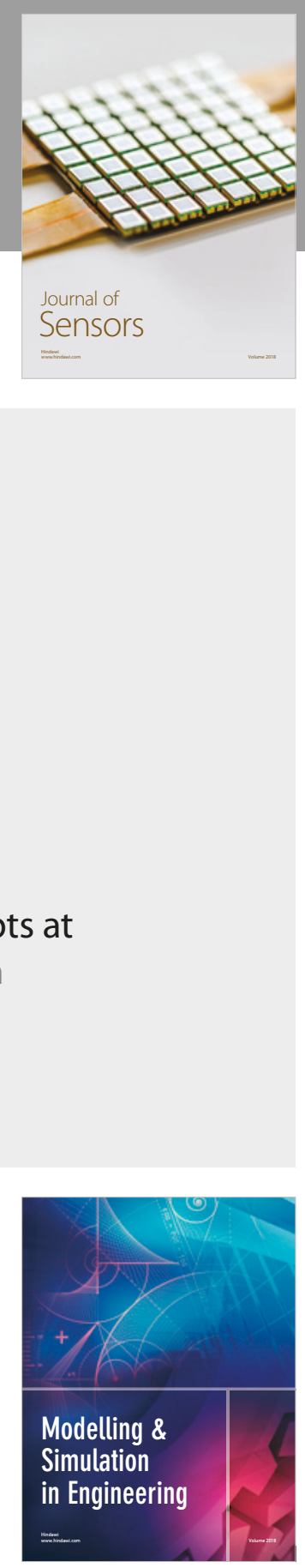

\section{Advances \\ Multimedia}
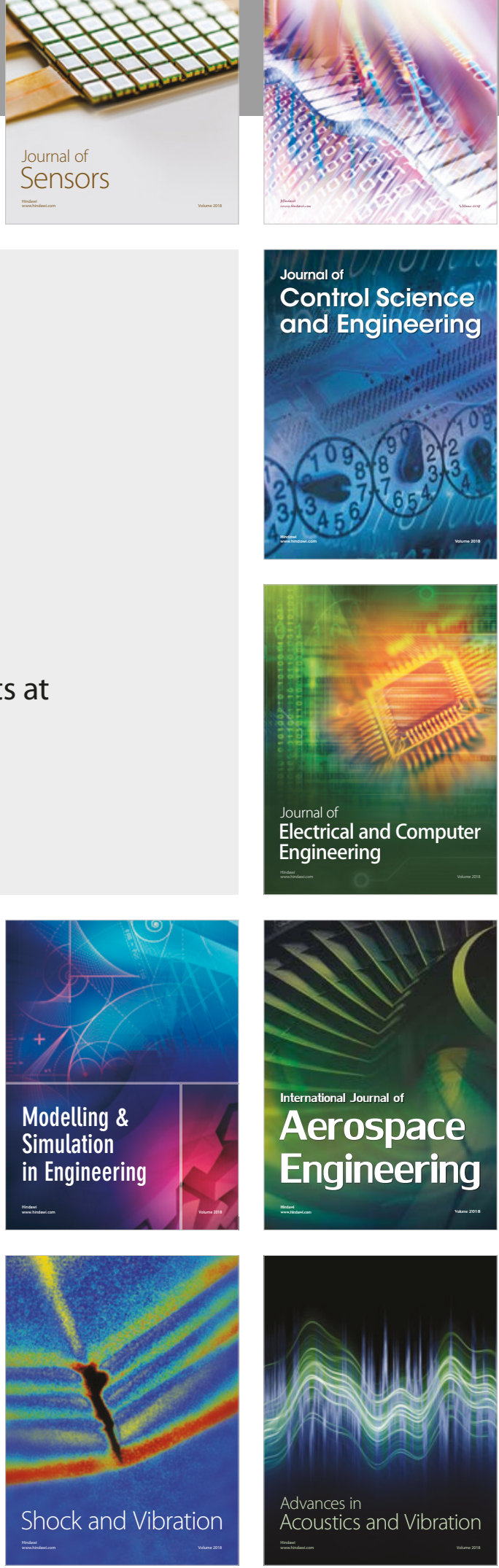